\title{
In silico characterization of GmSOS1 provides a comprehensive understanding for its role in soybean salt tolerance
}

\author{
Zhi-Chao Mei ${ }^{1, \dagger}$, Ling-Yan Yang ${ }^{2, \dagger}$, Zhi-Min Liu' ${ }^{1}$, Qi-Li Tang ${ }^{3}$, Xin-Zhao Hou ${ }^{4}$, Li-Jun Xie ${ }^{2}$, Zhu-Jun Wei ${ }^{1, *}$ \\ ${ }^{1}$ College of Life Science, Northeast Forestry University, Harbin 150040, China; ${ }^{2}$ College of Forestry, Northeast Forestry \\ University, Harbin 150040, China; ${ }^{3}$ College of Life Science, Heilongjiang University, Harbin 150080, China; ${ }^{4}$ College of \\ Science, Harbin University of Science and Technology, Harbin 150080, China
}

*Corresponding author: w1971115609@163.com

tThese authors contributed equally to this work

\begin{abstract}
Plant SOS1 encodes plasma membrane $\mathrm{Na}^{+} / \mathrm{H}^{+}$antiporter, which helps in the exclusion of $\mathrm{Na}^{+}$and improves plant salt tolerance. However, detailed studies of SOSI in the important oil crop, soybean (Glycine max), are still lacking. In the present study, we carried out a comprehensive in silico analysis of SOS1 in soybean. Referring to the analysis of physicochemical properties and structural characteristics, the GmSOS1 is an acidic protein with instability and hydrophobicity. Subcellular localization of GmSOS1 supports the presumption that GmSOS1 is a plasma membrane $\mathrm{Na}^{+} / \mathrm{H}^{+}$ antiporter. Post-translational modification site prediction indicates 4 amino acids that may be phosphorylated. Further, the protein-protein interaction network and co-functional network signify the potential role of GmSOS1 in salt stress tolerance. Although the interaction between GmSOS1 and GmHKT1 remains elusive, some of the intermediary signaling components of SOS pathway in soybean have been predicted. In addition, in silico expression analysis based on transcriptome datasets using publicly available database revealed that GmSOS1 was differentially expressed in tissues and different times. Due to the analysis of its regulation mechanism, we found transcription factors such as WRKY and ERF as well as three miRNAs can regulate the expression of GmSOS1. Phylogenetic analysis using the homologous amino acid sequence of SOS1s from 26 species was performed to study the conserved motifs among these SOS1 members. Overall, we provide an extensive analysis of the GmSOSI and it promises the primary basis for the study in development and response to salt tolerance.
\end{abstract}

Key words: bioinformatics; Glycine max; GmSOS1; expression profile; evolutionary analysis

\section{Introduction}

High concentrations of $\mathrm{Na}^{+}$in saline soils inhibit plant growth and reduce agricultural productivity ${ }^{[1]}$. Salt stress causes primary injuries, including osmotic effects at an early phase and ionic toxicity at a later phase of plant growth ${ }^{[2]}$. It can also induce the accumulation of reactive oxygen species (such as $\mathrm{O}^{2-}$ and $\mathrm{H}_{2} \mathrm{O}_{2}$ ), which will lead to secondary damages such as nutritional imbalance and oxidative stress ${ }^{[3-5]}$. Through long-term evolution, plants have developed diverse mechanisms to mitigate the destructive effects of salt stress through morphological, physiological and biochemical adjustments ${ }^{[6-7]}$. Sodium $\left(\mathrm{Na}^{+}\right)$is a common ion in soil, and excessive $\mathrm{Na}^{+}$outside of or accumulation in plant cells results in disturbance or imbalance of intracellular osmotic, ionic, and oxidative homeostasis ${ }^{[8]}$. Thus, it is essential for plants to prevent the accumulation of $\mathrm{Na}^{+}$and to maintain the appropriate $\mathrm{K}^{+} \mathrm{Na}^{+}$ratio in the cytoplasm, which is largely regulated via $\mathrm{Na}^{+}$ transporters ${ }^{[9-12,2]}$. SOS (Salt overly sensitive) pathway can specifically regulate cell sodium homeostasis, which is one of the most extensively studied plant salt stress signal transduction pathways ${ }^{[13]}$. Under high $\mathrm{Na}^{+}$stress, calcium-dependent 
bioRxiv preprint doi: https://doi org/10.1101/2020.02.21.951061; this version posted May $13,2020$. The copyright holder for this preprint (which was not certified by peer review) is the author/funder, who has granted bioRxiv a license to display the preprint in perpetuity. It is made available under aCC-BY 4.0 International license.

protein kinases in the SOS pathway mediate salt stress signals, and plants can adapt salt stress by effluxing $\mathrm{Na}^{+}$. The SOS pathway consisting of three components, the plasma membrane $\mathrm{Na}^{+} / \mathrm{H}^{+}$antiporter $\mathrm{SOS} 1$, the cytoplasmic protein kinase SOS2, and the $\mathrm{Ca}^{2+}$ sensor SOS3. SOS1 protein plays an important role in SOS pathway to efflux $\mathrm{Na}^{+}{ }^{+[14]}$. Up to now, a number of SOS1 homologous genes have been cloned and identified from a variety of different plants. The A. thaliana SOS1 protein (AtSOS1) is the first described plasma membrane-localized $\mathrm{Na}^{+} / \mathrm{H}^{+}$antiporter mediating $\mathrm{Na}^{+}$efflux and controlling long-distance $\mathrm{Na}^{+}$transport from roots to shoots ${ }^{[15]}$. When tomato (Solanum lycopersicum) SlSOSI was completely silenced, the plant showed a salt-sensitive phenotype with high $\mathrm{Na}^{+}$content in roots and leaves. However, when SISOS1 was specifically silenced in tomato stem vascular bundles, the plant showed a salt tolerance phenotype with low $\mathrm{Na}^{+}$ content, indicating that the SISOS1 protein mainly excreted $\mathrm{Na}^{+}$in tomato root cells ${ }^{[16]}$.

Soybean is the primary source of the world's supply of vegetable protein and oil. Demand for soybean has grown rapidly due to soybean's wide range of applications in food, feed, and industrial products. However, soybean production is threatened by several abiotic stresses, such as soil salinity. Soybean GmSOS1 can reduce primary $\mathrm{Na}^{+}$toxicity by limiting $\mathrm{Na}^{+}$accumulation and enhance antioxidant enzyme activity to reduce secondary oxidative stress ${ }^{[17]}$. In present study, a comprehensive bioinformatics analysis of soybean GmSOS1 gene was performed, which lays the foundation for further research on the biological properties and functions of soy and provides a theoretical basis for the future breeding of high-yield, salt-tolerant soybean varieties.

\section{Materials and methods}

\subsection{Genome-wide identification}

The plant SOS1 protein has an N-terminal $\mathrm{Na}^{+} / \mathrm{H}^{+}$exchanger domain (PF00999) and a long cytoplasmic tail at C-terminal end. The cytosolic moiety has the cyclic nucleotide-binding domain (PF00027) and the auto-inhibitory domain, which can regulate the transport activity. To identify the SOS1 gene in soybean, genome and proteome datestes were downloaded from Soybase ${ }^{[18]}$, and the Hidden Markov Model (HMM) profiles of the first two abovementioned domains were downloaded from Pfam 32.0 datebase $^{[19]}$. The two HMM profiles were used as query to search the soybean proteome with Hmmer 2.0(http://www.hmmer.org/).

\subsection{Analysis of protein sequence properties}

The protein sequence of GmSOS1 gene was used in ExPASy tools ${ }^{[20]}$ with standard parameters to calculate the physicochemical properties. Subcellular localization was predicted by WoLF PSORT ${ }^{[21]}$, Plant-mPLoc ${ }^{[22]}$ and ProtComp9.0 (http://www.softberry.com/) independently.

\subsection{Protein structure analysis}

Raptorx-propert ${ }^{[23]}$ and Netsurfp-2.0 $0^{[24]}$ were used to predict secondary structure, solvent accessibility and disordered regions of GmSOS1 protein. Typical domains were indentified by PfamScan ${ }^{[25]}$ and $\mathrm{CDD}^{[26]}$, the specification of the membrane spanning segments and their IN/OUT orientation relative to the membrane was predicted by TOPCONS ${ }^{[27]}$, and signal peptides was predicted by signalp-5.0 Server ${ }^{[28]}$. We aligned the protein sequences of GmSOS1 and AtSOS1 to deduce the location of auto-inhibitory domain in GmSOS1 ${ }^{[29]}$. The three-dimensional (3D) structure of GmSOS1 was generated by Raptor ${ }^{[30]}$, and $\mathrm{VMD}^{[31]}$ was used to visualize the structure. The ligand-binding site of CNBD was predicted by 3DligandSite ${ }^{[32]}$.

\subsection{Protein phosphorylation site analysis}

In order to ensure the high reliability of protein phosphorylation sites prediction results, local prediction software 
bioRxiv preprint doi: https://doi.org/10.1101/2020.02.21.951061; this version posted May 13,2020 . The copyright holder for this preprint (which was not certified by peer review) is the author/funder, who has granted bioRxiv a license to display the preprint in perpetuity. It is made available under aCC-BY 4.0 International license.

GPS5. $0^{[33]}$ and two online prediction services NetPhos 3.1Server ${ }^{[34]}$ and MusiteDeep ${ }^{[35-36]}$ were used independently for analysis. Among them, the confidence parameter of GPS5.0 was set as "high", NetPhos 3.1 Server only displays the residues whose scores were higher than 0.90, and the lowest specificity of each predicted site discovered by MusiteDeep was set as "90\%". The sites indicated by all the three results were selected.

\subsection{Protein function analysis}

The functional protein association network of GmSOS1 protein was predicted using the web program STRING ${ }^{[37]}$, the confidence parameter was set as "high confidence". Genes co-functioned with GmSOS1 gene were accessed by SoyNet ${ }^{[38]}$. Visualizing was performed with Cytoscape tool ${ }^{[39]}$.

\subsection{Expression profiles and its regulation mechanism}

\subsubsection{The spatio-temporal and stressed expression profiles of GmSOS1 gene}

Publicly available soybean transcriptome datasets from Phytozome v12.1 ${ }^{[40]}$ were used to investigate the expression pattern of GmSOS1 gene in nine different tissues including roots, root hairs, stems, nodules, apex meristem, leaves, flowers, pods, and seeds. The circadian transcriptome of soybean leaves (GSE94228), salt stress transcriptome of soybean leaves (GSE133574) and short-term phosphorus deficiency of soybean leaves (GSE104286) also been collected from NCBI $\mathrm{GEO}^{[41]}$. The GmSOS1 gene expression level was presented as FPKM (fragments per kilobase of exon per million fragments mapped). Two-tailed test was used for the comparison and $P<0.01$ was considered as statistically significant.

\subsubsection{Transcription factor analysis and miRNA predicted}

The upstream $2 \mathrm{~kb}$ sequences of the GmSOS1 from the translation start site were retrieved to analyze for the identifcation of transcription factors important for gene expression under abiotic stress using PlantPAN 3.0 $0^{[42]}$. We used the sRNAanno ${ }^{[43]}$ to study the role of miRNAs in regulating the expression of GmSOS1 gene.

\subsection{Conserved motif and phylogenetic analysis}

The homologous amino acid sequence of SOS1s from 26 species were derived from Phytozomev12.1 ${ }^{[40]}$ and BLAST program of $\mathrm{NCBI}^{[44]}$. They were then aligned using the MEGA ${ }^{[45]}$-MUSCLE ${ }^{[25]}$ program. Aferwards, a phylogenetic tree was constructed for the study of the these SOS1 members with the neighbor-joining(NJ) method. Bootstrap analysis was performed with 1000 replicates for statistical reliability. There were 26 species in the phylogenetic tree, comprising 15 SOS1s from Leguminosae (Glycine max、Glycine soja 、Vigna radiata、Spatholobus suberectus、Phaseolus vulgaris、Vigna angularis 、Vigna unguiculata 、Abrus precatorius、Cicer arietinum、Pisum sativum、Trifolium repens、Melilotus officinalis 、 Medicago truncatula、Lupinus angustifolius、Arachis hypogaea), 2 from Solanaceae (Oryza sativa、Brachypodium distachyon), 1 from Cruciferae (Arabidopsis thaliana), 1 from Bromeliad (Ananas comosus), 2 from Gramineae (Oryza sativa、Brachypodium distachyon),1 from Vitis(Vitis vinifera),1 from Rosaceae(Prunus persica), 1 from Myrtaceae (Eucalyptus grandis), 1 from Willow branch (Populus trichocarpa), and 1 from Mallow family(Gossypium raimondii). The motifs of these proteins were identified using the $\mathrm{MEME}^{[46]}$ program. The analysis was performed using "searching for six motifs" and the optimum motif width was set to 6-50 while the rest of the settings were kept as default.

\section{Results and analysis}

\subsection{Genome-wide identification}

There was only one gene encodes the protein which contained the $\mathrm{Na}^{+} / \mathrm{H}^{+}$exchanger domain and cyclic nucleotide -binding domain, it was located on Chr8(+):6947483-6960485. The exon number of GmSOS1 gene was 23. 
bioRxiv preprint doi: https:/doi org/10.1101/2020.02.21.951061; this version posted May 13,2020 . The copyright holder for this preprint (which was not certified by peer review) is the author/funder, who has granted bioRxiv a license to display the preprint in perpetuity. It is made available under aCC-BY 4.0 International license.

The results showed that the formula of this protein was $\mathrm{C}_{5708} \mathrm{H}_{8995} \mathrm{~N}_{1513} \mathrm{O}_{1650} \mathrm{~S}_{38}$, the molecular weight (Mw) was $12.64 \mathrm{kDa}$. The theoretical isoelectric value $(\mathrm{pI})$ was 6.30 , which revealed that it was an acidic protein. The GmSOS1 polypeptide was an 1143 amino acid sequence composition bias toward leucine (12.69\%). In addition, there was an apparent lack of tryptophan (1.40\%) and cysteine (1.14\%). The number of positively charged residues (Arg+Lys) was 104, while the number of negatively charged residues (Asp+Glu) was 117 (Figure1). The instability index (II) of GmSOS1 was computed to be 42.61 , this classified the protein as unstable. The grand average of hydropathicity (GRAVY) was 0.089 , implying that it was hydrophilic protein. The Aliphatic index (AI) is 102.29, which also proves GmSOS1 is hydrophilic protein. All three subcellular localization prediction methods showed that GmSOS1 was localized at the plasma membrane, consistent with the presumption that $\mathrm{GmSOS} 1$ protein is a plasma membrane $\mathrm{Na}^{+} / \mathrm{H}^{+}$antiporter.

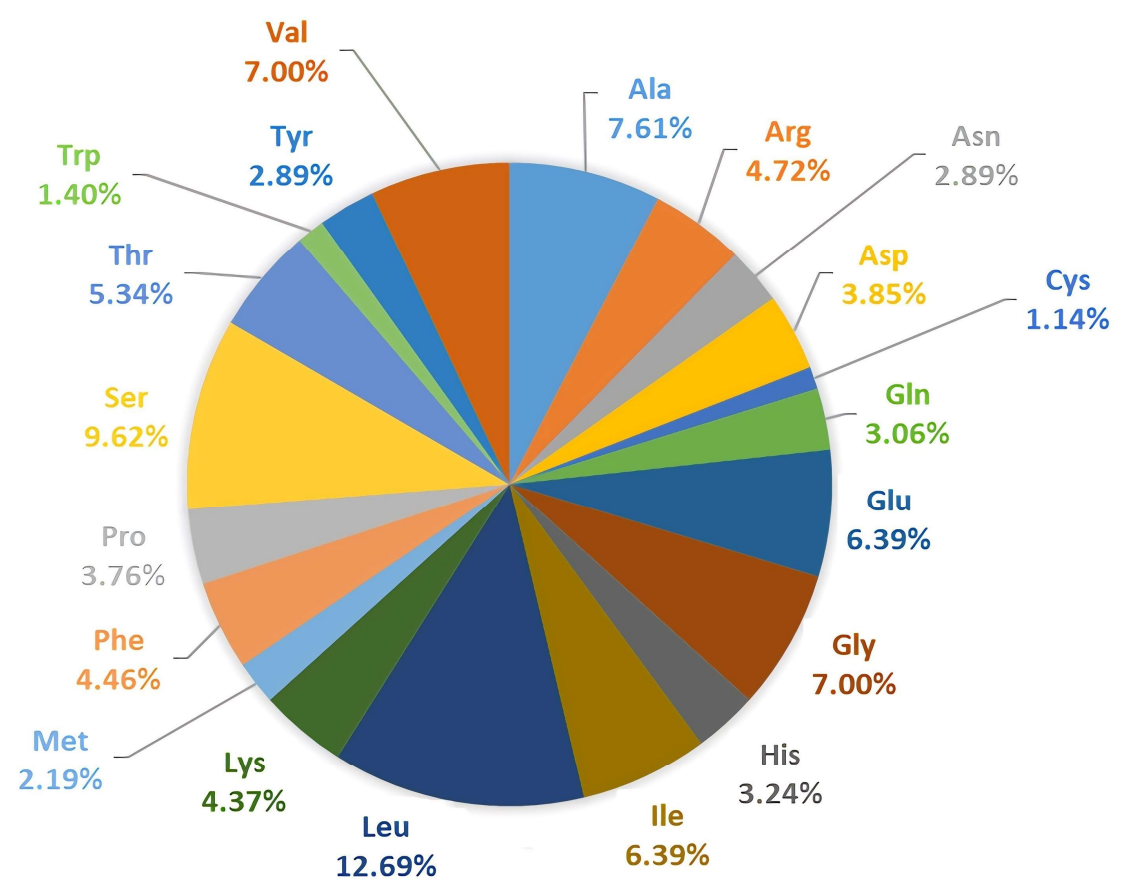

Figure 1 amino acid composition of GmSOS1 protein

\subsection{Protein structure analysis}

The deduced secondary structure of GmSOS1 protein indicated that it formed of $54 \%$ helixes, $7 \%$ strands and $37 \%$ coils. The amino acids exposed to the protein surface and embedded in the protein accounted for $49 \%$ and $23 \%$ of the total amino acids, respectively. $20 \%$ of the amino acids constituted the disordered region of the protein structure. The N-terminal of the protein accounted for about two-thirds of the total peptides was mainly composed of helixes, the near-C-terminal in the middle occupied one-sixth of the total peptides and consisted of two strand regions and a helical region separating them. 1/6 positions in the C-teminal predicted as disordered with high solvent accessibility (Figure 2). $\mathrm{The}^{+} \mathrm{Na}^{+} \mathrm{H}^{+}$exchanger domain was located at the N-terminal (32-464) which included 13 transmembrane regions (TM1:32-52, TM2:58-78, TM3:95-115, TM4:128-148, TM5:158-178, TM6:194-214, TM7:227-247, TM8:278-276, TM10:314-334, TM11:351-407, TM13:425-445). A cyclic nucleotide-binding domain was found near C-terminal (763-844). GmSOS1 protein also contained a C-terminal auto-inhibitory domain (994-1143). Signalp-5.0 Server showed no significant signal peptides (Figure 3A). The visualized 3D structure of the protein was shown (Figure 3B). The $\mathrm{N}$-terminal of the $\mathrm{Na}^{+} / \mathrm{H}^{+}$exchanger domain was a hydrophobic structure, and the C-terminal had a hydrophilic tail. The ligand CMP of the CNBD domain was bound to a hydrophobic pocket on the surface of the domain (Figure 3C). 
bioRxiv preprint doi: https://doi.org/10.1101/2020.02.21.951061; this version posted May 13, 2020. The copyright holder for this preprint (which was not certified by peer review) is the author/funder, who has granted bioRxiv a license to display the preprint in perpetuity. It is made available under aCC-BY 4.0 International license.

MEEEQQQQHLSLSISLSVVSAASSSSEENSNPSDAVIFFGLSLALGIACRHLLRGTRVPYTVALLILGIALGSIEYGTHH

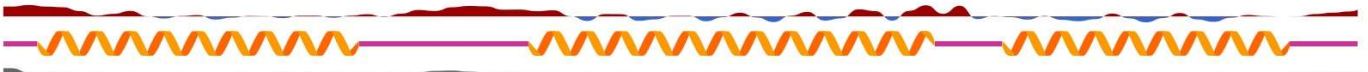

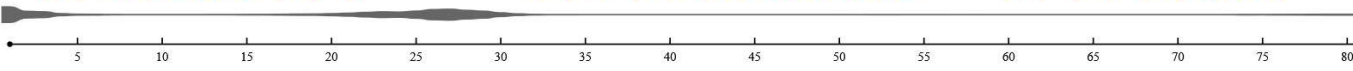
RLGKIGDGIRIWSEIDPDLLLAVELPALLFES SFLMEVHQIKRCLAQMILLAGPGVALSTVCLGVVLKLTFPYNWSWKTS

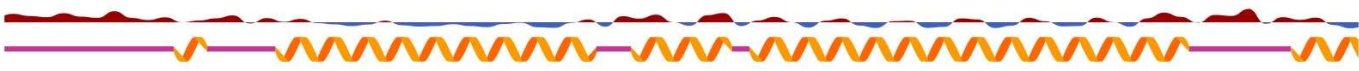

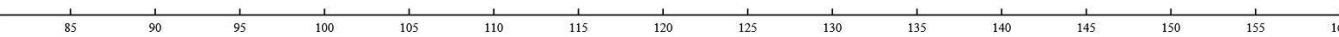

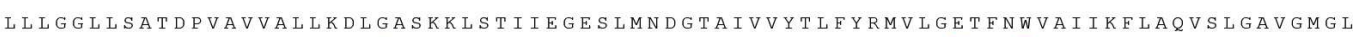

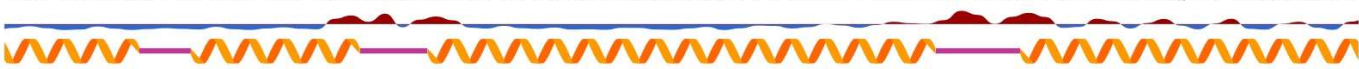

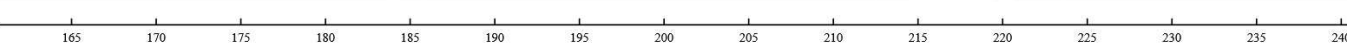
AFGIASVLWLGFIFNDTVIEIALTFAVSYIAYFTAQEGSGVSGVLTVMSLGMFYSAFARTAFKGSQQSLHHFWMIAYI

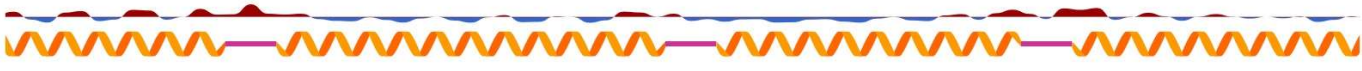

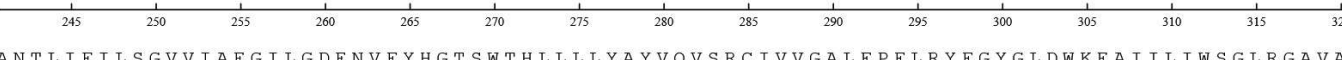
Nmvinn

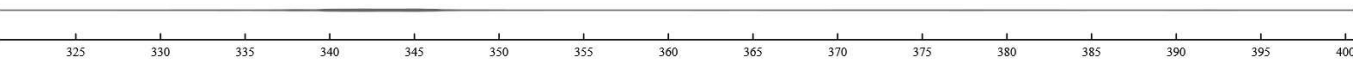
LALSLSVKRSGGKSSELTPETGTLFVEFTGGTVFLTLIINGST T FILHYLGMDKLSAAKRRILNFTKYEMLNKALEAFG

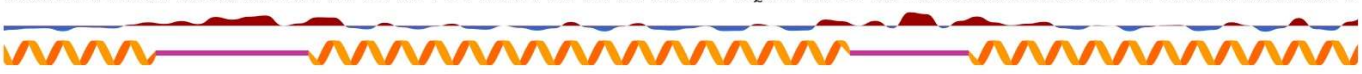

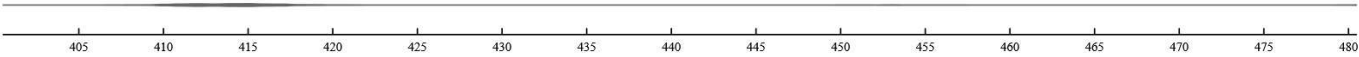
ELGDDEELGPADWPTVKRYISCLNDIEGECVHPHGAPENDSNLDPMNLKDIRVRLLNGVQAAYWEMLDEGRISQTTANIL n-

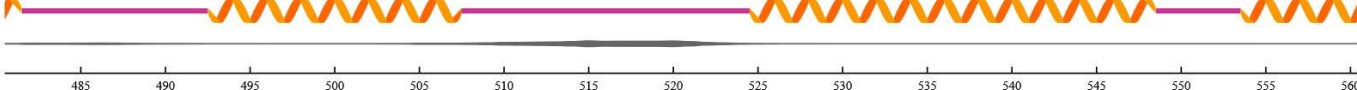
MLSVEEAVDLASSEPLCDWKGLKSNVHFPNYYKFL QSSMEPRKLVTYFTVERLESACYICAAFLRAHRIRQQLHDFIGD

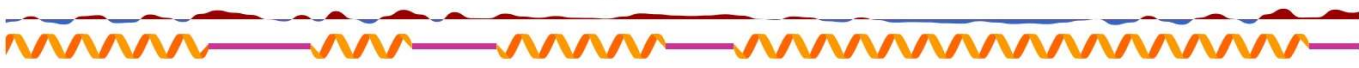

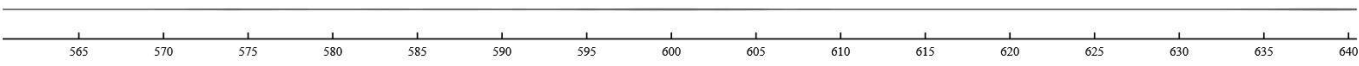

SDIASAVINESVVEGEEARKELEDVNVTYPQVLRVVKTRQATYAVLNHLIEYVENLEKAGILEEKEMLQLHDAVQTDLKK

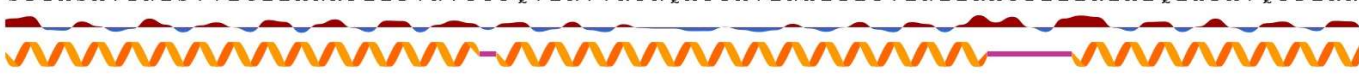

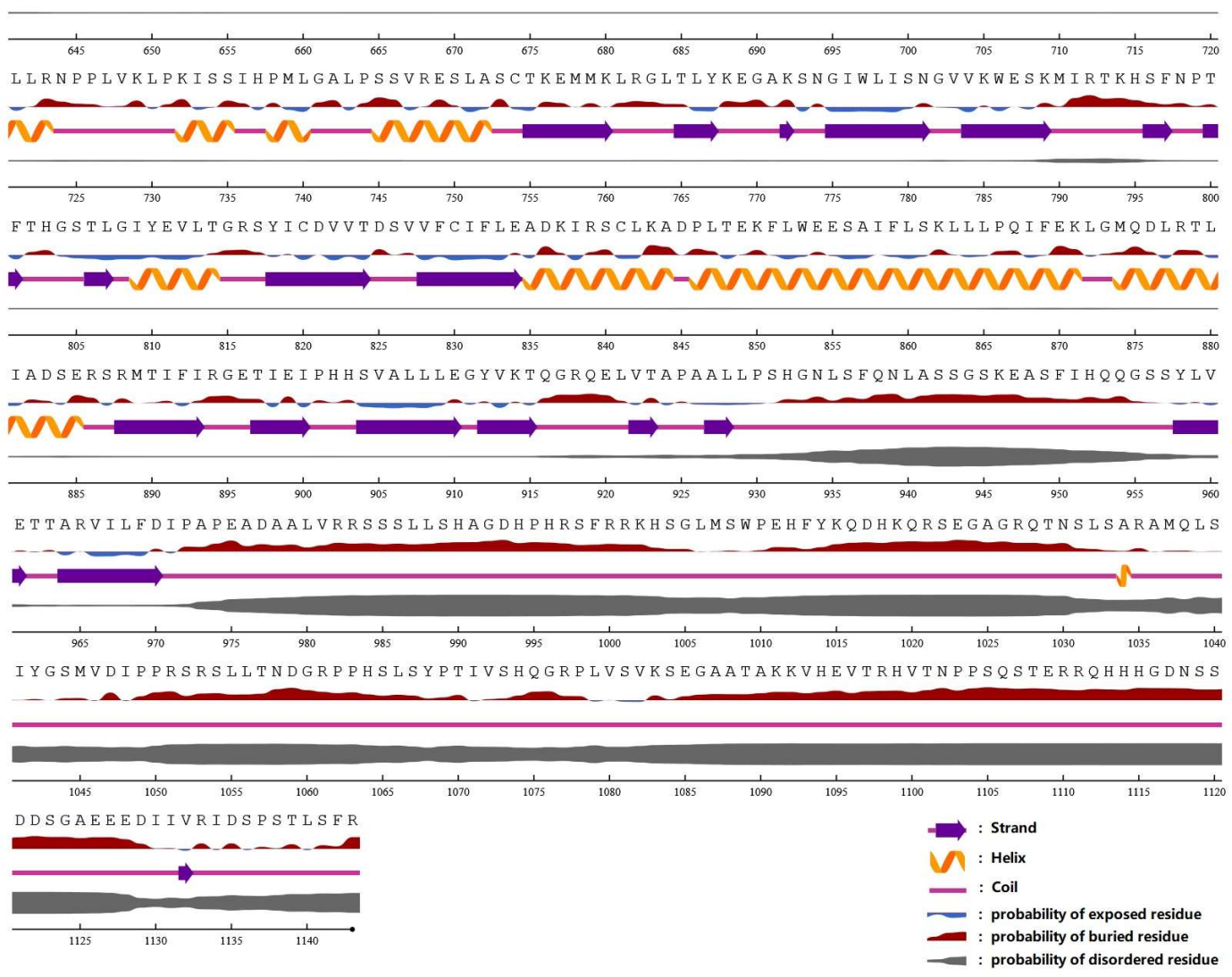


bioRxiv preprint doi: https://doi.org/10.1101/2020.02.21 951061; this version posted May 13, 2020. The copyright holder for this preprint (which was not certified by peer review) is the author/funder, who has granted bioRxiv a license to display the preprint in perpetuity. It is made available under aCC-BY 4.0 International license.

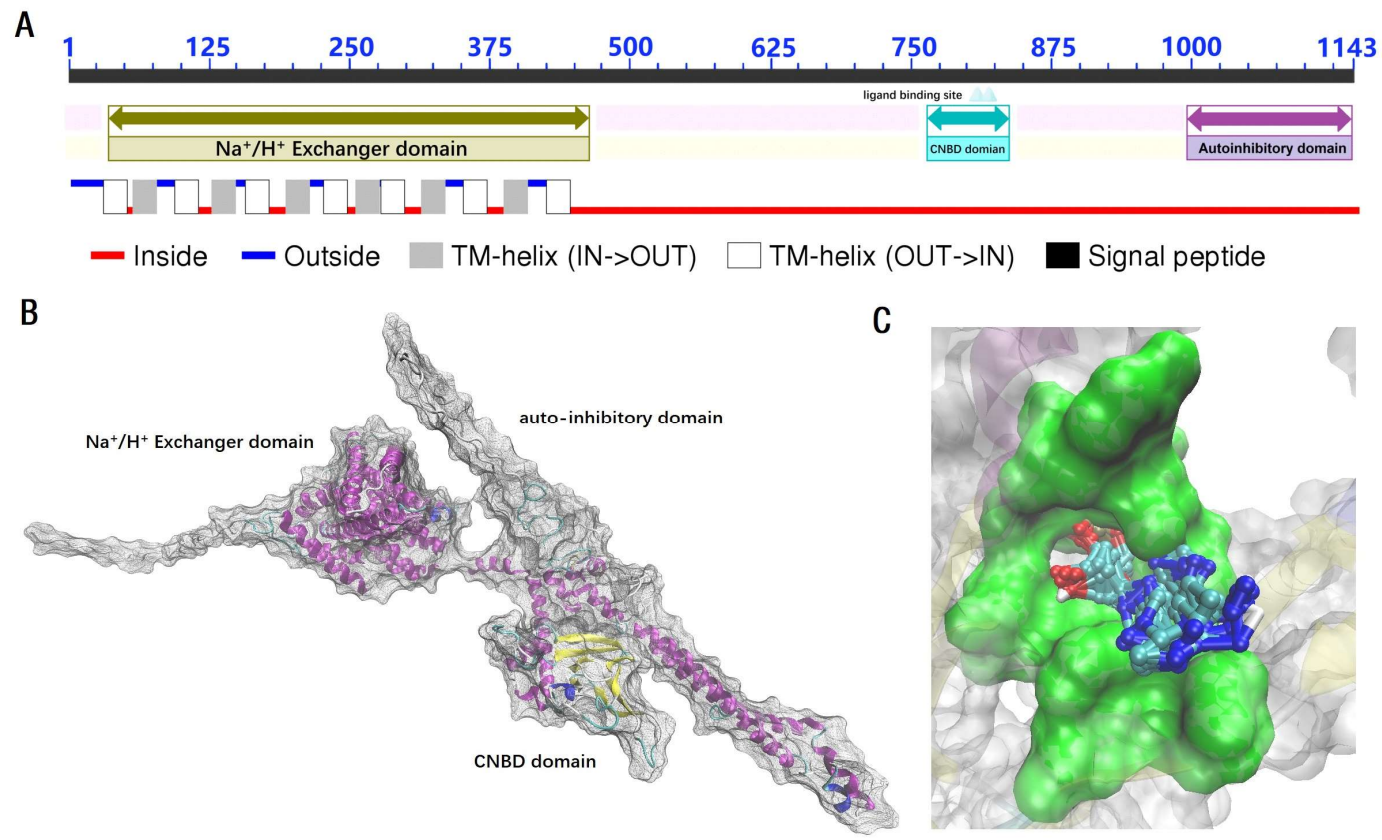

Figure 3 protein structure of GmSOS1

\subsection{Protein phosphorylation site analysis}

All three methods for putative phosphorylation sites in GmSOS1 identified several consensus sequences at the C-terminal hydrophilic domain, and the amino acid positions were S24, S414, S985, S1119, S1123, and S1136, respectively. Further transmembrane domain analysis showed that only the last four serines residues are target phosphorylation sites in the cytoplasm which may play an important role in the regulation of GmSOS1 protein activity (Figure 4).

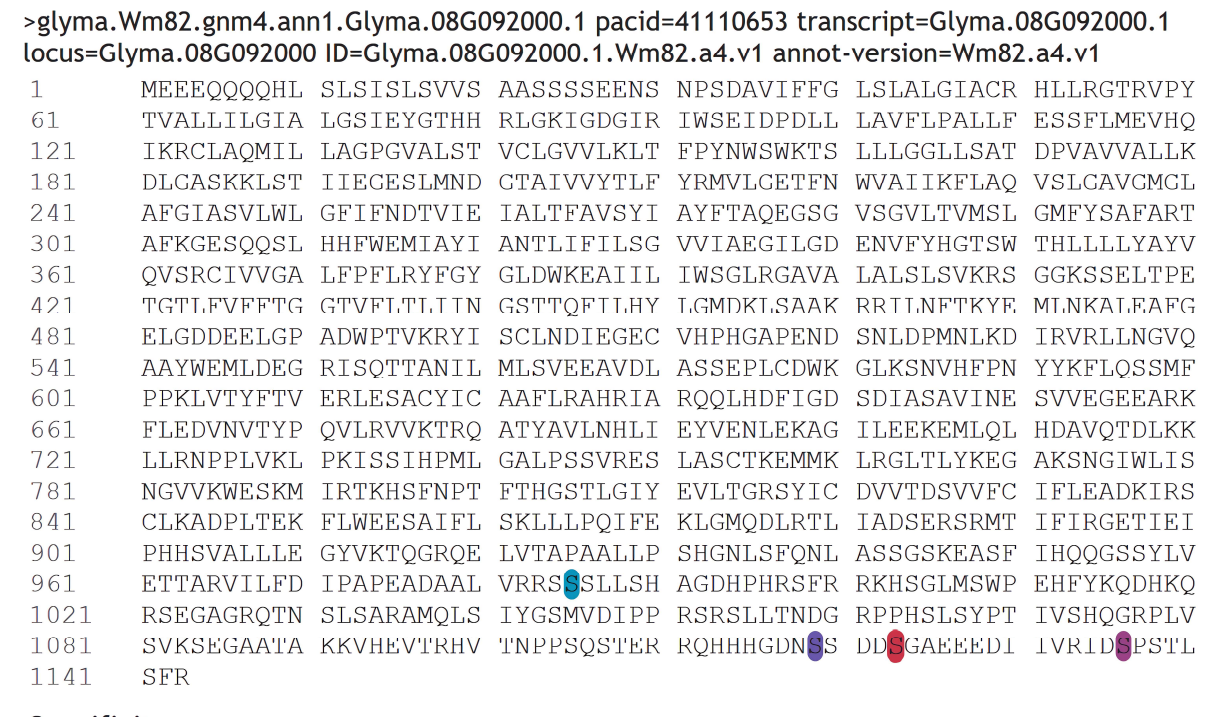

Specificity

$\begin{array}{lll}0 \% & 50 \% & 100 \%\end{array}$

Figure 4 phosphorylation sites of GmSOS1 protein

\subsection{Protein function analysis}

The functional protein association network was predicted in order to gain a better understanding of GmSOS1 protein role in soybean. The results showed that GmSOS1 protein was mapped to 10 unknown proteins that participated in the interaction network (Figure 5A). Comparative analysis of homologs between Arabidopsis and soybean may be helpful for the understanding of homologous gene functions in soybean. Our results showed that Glyma.01G002300.2, Glyma.06G271600.1,Glyma.07G130100.2,Glyma.12G133400.1 and Glyma.17G31011.1 (Wm82.a1.v1) might be function 
bioRxiv preprint doi: https://doi.org/10.1101/2020.02.21.951061; this version posted May 13, 2020. The copyright holder for this preprint (which was not certified by peer review) is the author/funder, who has granted bioRxiv a license to display the preprint in perpetuity. It is made available under aCC-BY 4.0 International license.

as $A$. thaliana AtHKT1 (High-affinity $\mathrm{K}^{+}$channel transporter). The $\mathrm{K}^{+}-\mathrm{Na}^{+}$co-transporter $\mathrm{HKT} 1$ also functions in $\mathrm{Na}^{+}$ influx under salt stress ${ }^{[47]}$, while SOS1 is a $\mathrm{Na}^{+}$-efflux transporter. At the same time, a high cytosolic $\mathrm{K}^{+} / \mathrm{Na}^{+}$ratio is essential for maintaining cellular metabolism ${ }^{[48]}$, and the regulation mechanism between SOS1 and HKT1 remains to be explored. Glyma.17G229500.1 and AtCBL10 shared the conserved EF-hand calcium binding domain. It is worthy to note that the RST and PARP domains were found in Glyma.01G015000.8 and Glyma.09G207200.4 as well as AtRCD1. Glyma.10G018000.1 had the $\mathrm{Na}^{+} / \mathrm{Ca}^{2+}$ exchanger domain. Glyma.01G015200.2 had no special domain. Co-functional networks are useful for identifying genes that are involved in a particular pathway or phenotype. To understand the interactions of GmSOS1 genes with its neighbors and to get more insights into its function, a gene correlation network was constructed. It can be seen that the GmSOS1 may be directly related to 12 genes (Figure 5B), nine of which are widely connected with other genes in gene co-functional network and regulated diverse biological processes and pathways. Notably, the co-functional network was divided into 4 clusters. In cluster I, Glyma.06G128700 is the homologous gene of AtCBL4 (SOS3) and Glyma.04G235900 is the homologous gene of AtCBL7. In cluster II, Glyma.17G113700 and Glyma.13G166100 are homologous genes of AtCIPK24 (SOS2) annotated in Soybase. Cellular calcium signals are detected and transmitted by sensor molecules such as calcium-binding proteins. In plants, the calcineurin B-like protein (CBL) family represents a unique group of calcium sensors and plays a key role in decoding calcium transients by specifically interacting with and regulating a family of protein kinases $(\mathrm{CIPKs})^{[49]}$. Based on two proven salt tolerance pathways in Arabidopsis, one is the phosphorylation of $\mathrm{Na}^{+} / \mathrm{H}^{+}$antiporter SOS1 on the plasma membrane by the AtCBL4 (SOS3)-AtCIPK24 (SOS2) kinase complex brings about substantial activation of SOS1 to enhance $\mathrm{Na}^{+}$exclusion ${ }^{[50]}$, and the other is through AtCBL10-AtCIPK24 (SOS2) kinase complex phosphorylates $\mathrm{Na}^{+} / \mathrm{H}^{+}$antiporter $\mathrm{NHX}$ on the vacuolar membrane ${ }^{[51]}$. In this study, GmCBL4 has the same fun ction as SOS3, GmCBL10 has the same function as $A t C B L 10$, and a new $G m C B L 7$ with similar function as SOS3 is predicted. Glyma.01G015000, Glyma.09G207200 and Glyma.01G15200 are in cluster 3, all of which are homologous genes of AtRCD1. In protein-protein interaction analysis, it can be seen that the proteins encoded by the first two genes interact with GmSOS1. It was found that the AtRCD1 in Arabidopsis was mainly involved in plant regulation of salt stress through two pathways. One is a function in the nucleus. It has been shown that $R C D 1$ interacts with transcription factors such as STO and DREB2A, which have been implicated in salt-stress tolerance ${ }^{[52]}$. Another function of RCD1 is performed in the cytoplasm and near the cell periphery and is possibly related to its interaction with SOS1, the biochemical consequence of RCD1-SOS1 interaction is not known ${ }^{[53]}$. Glyma.05G097300 encoded type D cyclin, which was localize to the nucleus. Glyma.08G219500 encoded glycosyltransferase. Glyma.08G165800 was a protein kinase, the function of Glyma.09G259200 and Glyma.06G027800 were unknown.

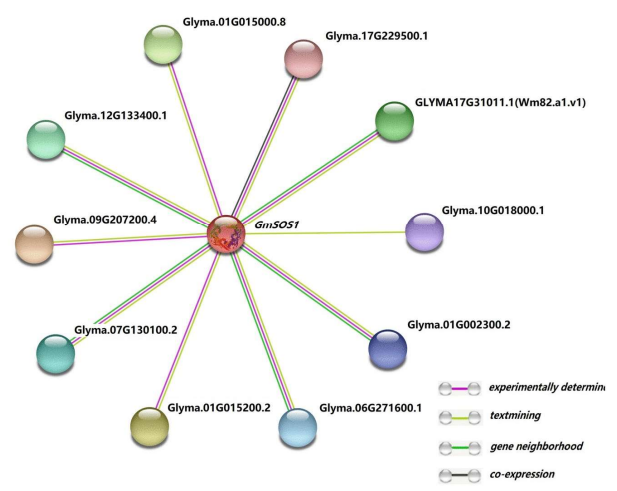

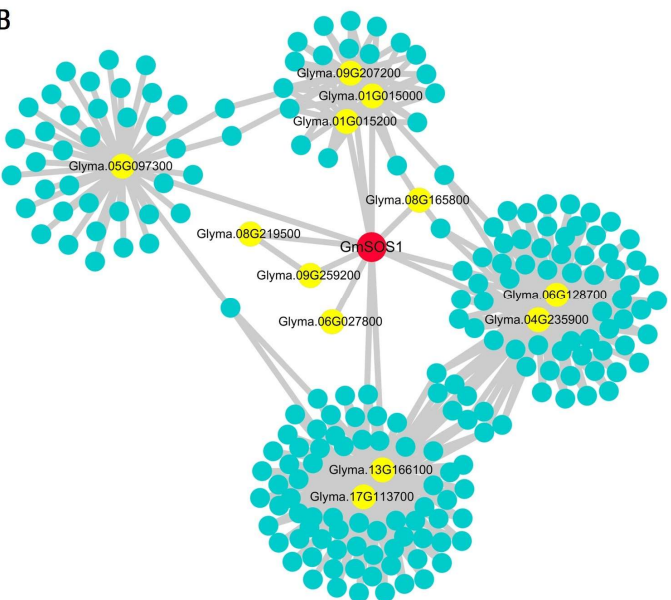

Figure 5 The functional protein association network and co-functional network of GmSOS1 


\subsection{Expression profiles and its regulation mechanism}

\subsubsection{The spatio-temporal and stressed expression profiles of GmSOS1 gene}

GmSOS1 showed the highest level of expression in roots and the lowest in leaves (Figure 6A). On the whole, the expression levels of GmSOS1 varied at different time, suggesting that the expression of GmSOS1 may have circadian rhythm (Figure 6B). GmSOS1 was slightly up-regulated $(p>0.01)$ when treated with phosphorus deficiency in soybean leaves (Figure 6D). However, it was significantly induced in root $(p<0.01)$ under salt stress, which indicates its role involved in salt responses (Figure 6C).
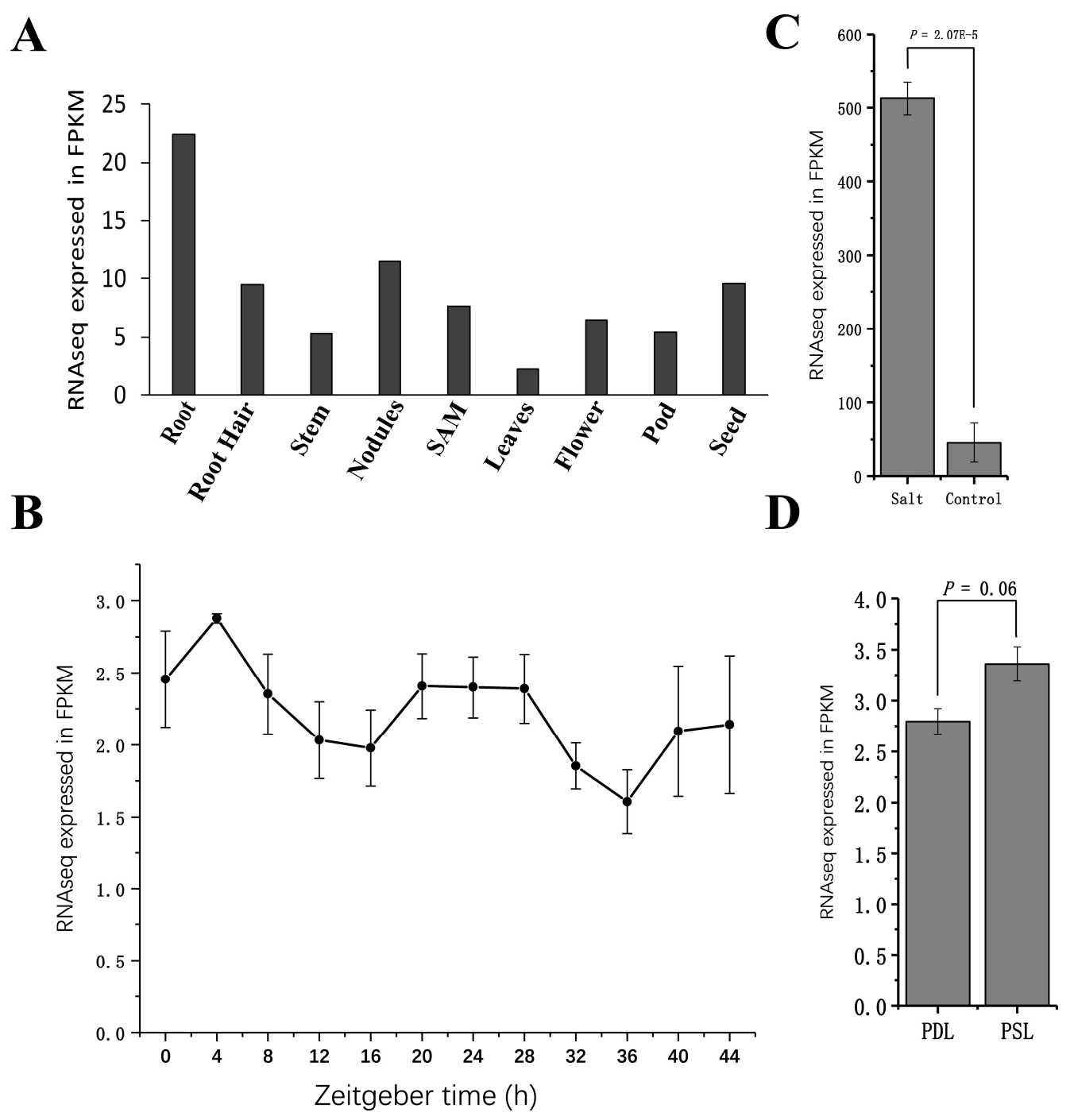

Figure 6 The spatio-temporal and stressed expression profiles of GmSOS1 gene

PDL: phosphorus deficiency in leaves PSL:phosphorus deficiency in leaves(means \pm SDs)

\subsubsection{Transcription factor analysis and miRNA predicted}

The results showed that 27 transcription factors that participated in the regulation of GmSOS1, including 2 ARR-B families, $1 \mathrm{bZIP}$ family, $2 \mathrm{C} 2 \mathrm{H} 2$ families, 4 ERF families, $3 \mathrm{HD}$-zip families, 1 MIKC-MADS family, $1 \mathrm{MYB}-$ related family, 2 NAC families, 1 TBP family, and 11 WRKY families (Figure 7). GmWRKY47 transcription factor was identified from the soybean genome via a genome-wide study, Yu et al. ${ }^{[54]}$ found that Glyma.09G080000 encoded by GmWRKY47 was involved in the response to salt stress. In this study, we found that the GmWRKY47 can probably target GmSOS1, which may be a potential mechanism for GmWRKY47 to participate in salt stress response. We predicted GmSOSI gene as potential target of 3 miRNAs: Gma-mir1508, Gma-mir395, and Gma-mir166 (Figure 7). 


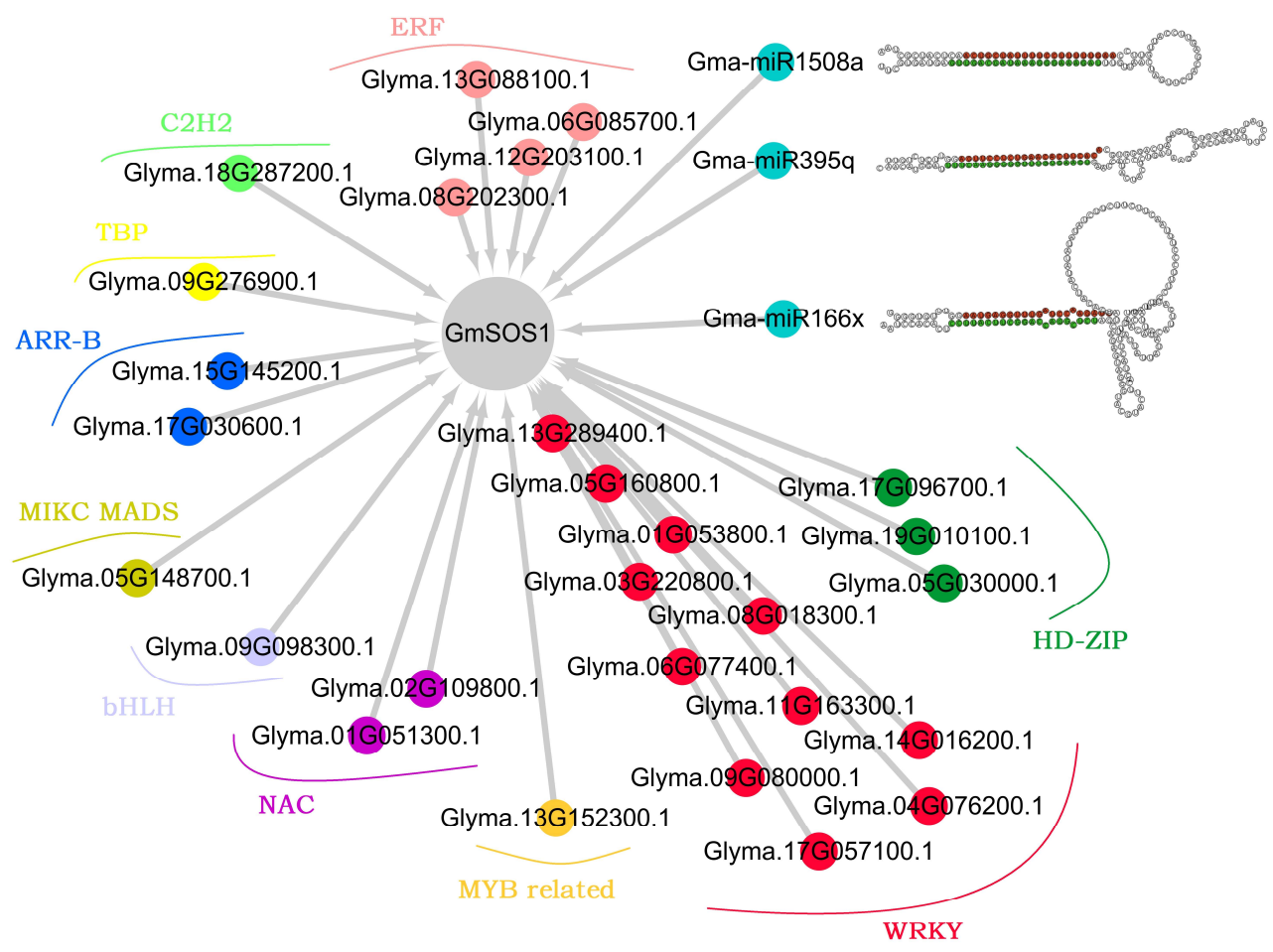

Figure 7 transcription factors and miRNAs that regulate GmSOS1

\subsection{Conserved motif and phylogenetic analysis}

The results of conserved motif analysis showed that the motifs $2 \sim 7$ were shared by all SOS1 members, indicating that these motifs are highly conserved in SOS1 (Figure 8). They might be responsible for different biological functions in these SOS1s. Motif2 and motif3 presented in the $\mathrm{Na}^{+} / \mathrm{H}^{+}$exchanger domain of SOS1s. Motif4、5、6 and 7 existed in cyclic nucleotide-binding domain. The conserved C-terminal region harbored more motifs than N-terminal.

Comparative analysis of homologs between Glycine max and Glycine soja may be helpful for the understanding of homologous protein function in soybean. Our results showed that GmSOS1 and GsSOS1 are clustered into a same branch in the phylogenetic tree (Figure 8), implicating that GmSOS1 protein might be function as GsSOS1. Clearly, protein form Glycine max showed more distantly evolutionary relationship with Gossypium raimondii and Populus trichocarpa, indicating that the differentiation time between them may be the longest, or the selection pressure of SOS1 protein among them is quite different.
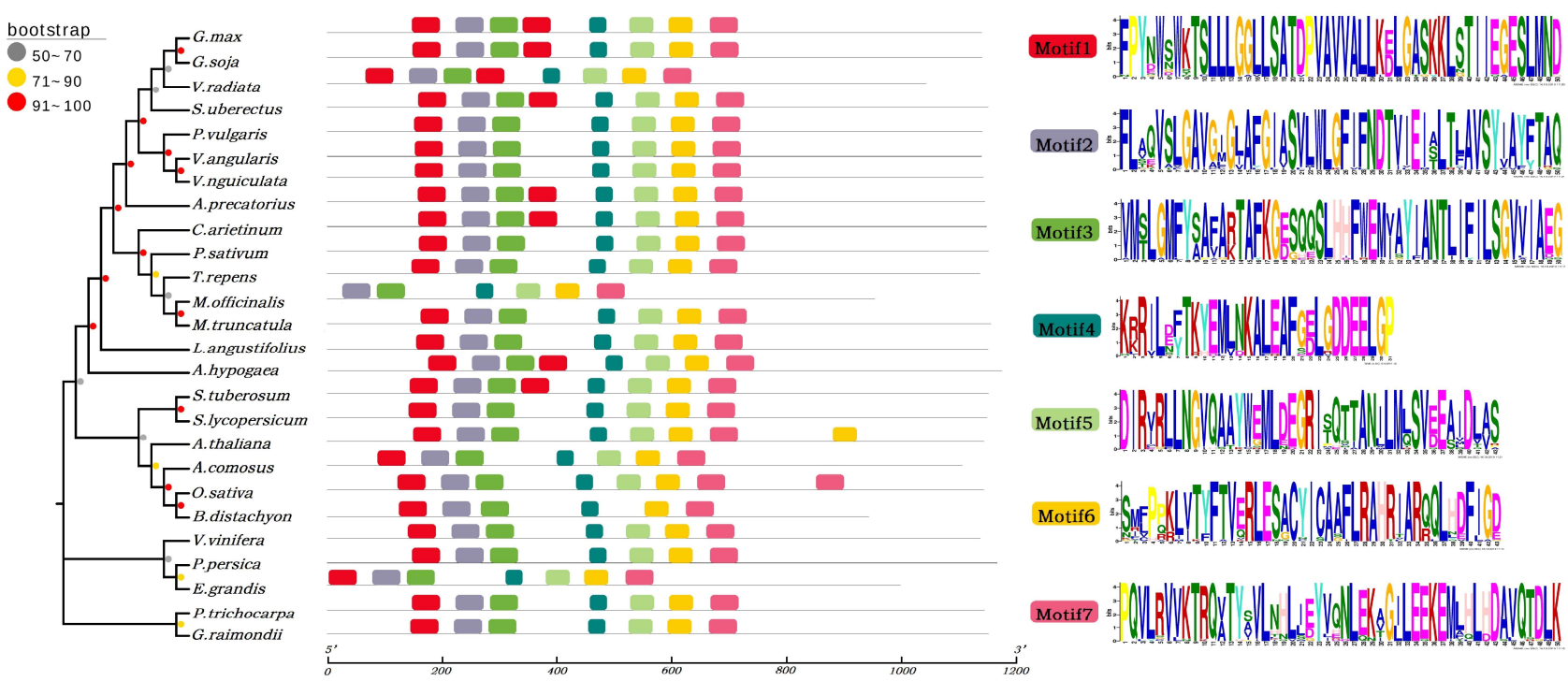

Figure 8 phylogenetic tree and comparison analysis of the conserved motif of SOS1 protein 
bioRxiv preprint doi: https://doi.org/10.1101/2020.02.21.951061; this version posted May 13, 2020. The copyright holder for this preprint (which was not certified by peer review) is the author/funder, who has granted bioRxiv a license to display the preprint in perpetuity. It is made available under aCC-BY 4.0 International license.

\section{Conclusion}

The plasma membrane $\mathrm{Na}^{+} / \mathrm{H}^{+}$exchanger SOS1 (salt-overly-sensitive 1) is a critical salt tolerance determinant in plants. In this study, a systematic analysis was executed to study the GmSOS1 gene. Subcellular localization confirmed that soybean GmSOS1 gene is localized at the plasma membrane, which is consistent with the presumption that GmSOS1 is a plasma membrane $\mathrm{Na}^{+} / \mathrm{H}^{+}$antiporter. Domain analysis showed that soybean $\mathrm{GmSOS} 1$ protein has a $\mathrm{Na}^{+} / \mathrm{H}^{+}$exchanger domain, a cyclic nucleotide-binding domain, and an auto-inhibitory domain, which are closely related to the function of SOS1 protein to efflux $\mathrm{Na}^{+}$. The prediction of the phosphorylation sites combined with the analysis of the transmembrane domain indicates that there are four phosphorylation sites in the soybean GmSOS1 protein, and they are likely to be target sites for protein kinase to regulate GmSOS1 transport activity. The gene co-functional network predicted that $G m C B L 4$ has the same function as $S O S 3$, GmCBL10 has the same function as $A t C B L 10$, and a new GmCBL7 that may have similar functions as SOS3. The expression of GmSOS1 gene is spatio-temporal specific, and a variety of transcription factors and miRNAs can regulate its expression. We found that GmWRKY47 may regulate its transcription by binding to the promoter of GmSOS1, which provides an idea for the mechanism study of GmWRKY47 participating in the response to salt stress. In the analysis of 26 homologous proteins, the highly conserved motif2 motif7 suggests that the core functional sites of SOS1 might be composed of them. Phylogenetic analysis showed that GmSOS1 is more closely related to GsSOS1. Soybean is an important oil crop, the results of this work are helpful to study the growth and development of soybean under salt stress. Our present study raises several interesting questions that need to be addressed in the future, for example, 1) How GmSOSI and $H K T 1$ work together to regulate intracellular $\mathrm{K}^{+} / \mathrm{Na}^{+}$balance, 2) How the complex formed by the hydrophilic tail of GmSOS1 and RCD1 plays a role in resisting salt stress, 3) How cyclins are involved in the GmSOS1 regulatory pathway, 4) What role the predicted transcription factors play in the regulation of GmSOS1.

\section{References}

[1]Huazhong Shi, Byeong-ha Lee, Shaw-Jye Wu. Overexpression of a plasma membrane $\mathrm{Na}^{+} / \mathrm{H}^{+}$antiporter gene improves salt tolerance in Arabidopsis thaliana[J]. Nat Biotechnol, 2003, 21(1): 81-5.

[2]Sanadhya P, Agarwal P, Agarwal PK. Ion homeostasis in a saltsecreting halophytic grass[OL]. AoB Plants, 2015, 7: plv055.doi: 10.1093/aobpla/plv055.

[3]Manchanda G, Garg N. Salinity and its effects on the functional biology of legumes[J]. Acta Physiol Plant, 2013, 12(11): 4670-84.

[4]de Oliveira AB, Alencar NL, Gomes-Filho E. Comparison between the water and salt stress effects on plant growth and development[OL]. InTech Open, 2012, doi: 10.5772/54223

[5] He Y, Fu J, Yu C, et al. Increasing cyclic electron flow is related to $\mathrm{Na}^{+}$sequestration into vacuoles for salt tolerance in soybean[J]. J Exp Bot, 2015, 66(21): 6877-89.

[6]Qiu ZB, Guo JL, Zhu AJ, et al. Exogenous jasmonic acid can enhance tolerance of wheat seedlings to salt stress[J]. Ecotox Environ Safe, 2014, 104: 202-208.

[7]Schmidt R, Mieulet D, Hubberten H-M, et al. Salt-responsive ERF1 regulates reactive oxygen species-dependent signaling during the initial response to salt stress in rice[J]. Plant Cell, 2014, 25: 2115-2131

[8]Adem GD, Roy SJ, Zhou M, et al. Evaluating contribution of ionic,osmotic and oxidative stress components towards salinity tolerance in barley[J]. BMC Plant Biol, 2014, 14: 113 
bioRxiv preprint doi: https://doi org/10.1101/2020.02.21.951061; this version posted May 13, 2020. The copyright holder for this preprint (which was not certified by peer review) is the author/funder, who has granted bioRxiv a license to display the preprint in perpetuity. It is made available under aCC-BY 4.0 International license.

[9]Xue Z, Zhao S, Gao H, er al. The salt resistance of wild soybean(Glycine soja Sieb.et Zucc.ZYD 03262)under NaCl stress is mainly determined by $\mathrm{Na}^{+}$distribution in the plant[J]. Acta Physiol Plant, 2014, 36: 61-70

[10]Liu M, Wang T-Z, Zhang W-H. Sodium extrusion associated with enhanced expression of SOS1 underlies different salt tolerance between Medicago falcata and Medicago truncatula seedlings[J]. Environ Exp Bot, 2015, 110: 46-55.

[11] Volkov V. Salinity tolerance in plants. Quantitative approach to ion transport starting from halophytes and stepping to genetic and protein engineering for manipulating ion fluxes[J]. Front Plant Sci , 2015 ;6: 873

[12] Wu H, Shabala L, Liu X, et al. Linking salinity stress tolerance with tissue-specific $\mathrm{Na}^{+}$sequestration in wheat roots[J]. Front Plant Sci, 2015, 6: 71

[13]Zhu JK. Salt and drought stress signal transduction in plants[J]. Annu Rev Plant Biol, 2002, 53: 247-273.

[14]Li Xiaoyuan, Xie linan. Advances in the mechanism of $\mathrm{Na}^{+}$regulation in plants under salt stress[J]. Biotechnology bulletin, 2019, 35(07): 148-155.(in Chinese)

[15] Shi H, Quintero FJ, Pardo JM, et al. The putative plasma membrane $\mathrm{Na}^{+} / \mathrm{H}^{+}$antiporter SOS1 controls long-distance $\mathrm{Na}^{+}$transport in plants[J]. The Plant Cell, 2002, 14(2): 465-477.

[16]Olías R, Eljakaoui Z, Li J, et al. The plasma membrane $\mathrm{Na}^{+} / \mathrm{H}^{+}$antiporter SOS1 is essential for salt tolerance in tomato and affects the partitioning of $\mathrm{Na}^{+}$between plant organs[J]. Plant,Cell\&Environment, 2009, 32(7): 904-916.

[17]Xiufang Zhao, Peipei Wei, Zhen Liu. Soybean $\mathrm{Na}^{+} / \mathrm{H}^{+}$antiporter GmsSOS1 enhances antioxidant enzyme activity and reduces $\mathrm{Na}^{+}$accumulation in Arabidopsis and yeast cells under salt stress[J]. Acta Physiol Plant, 2017, 39: 19

[18]Grant, D., Nelson, R.T., Cannon, S.B., et al. SoyBase, the USDA-ARS soybean genetics and genomics database[J]. Nucleic Acids Research, 2010, 38 (suppl 1): D843-D846.

[19]S. El-Gebali, J. Mistry, A. Bateman, et al. The Pfam protein families database in 2019[J]. Nucleic Acids Research, 2019, Volume 47, Issue D1: 427-432.

[20]Gasteiger E., Hoogland C., Gattiker A., et al. Protein Identification and Analysis Tools on the ExPASy Server;(In) John M. Walker (ed): The Proteomics Protocols Handbook, Humana Press,2005, pp: 571-607.

[21]Paul Horton, Keun-Joon Park, Takeshi Obayashi, et al. WoLF PSORT: protein localization predictor[J], Nucleic Acids Research, 2007, Volume 35: W585-W587.

[22]Kuo-Chen Chou, Hong-Bin Shen. "Plant-mPLoc: a top-down strategy to augment the power for predicting plant protein subcellular localization"[J]. PLoS ONE, 2010, 5: e11335.

[23]Sheng Wang, Wei Li, Shiwang Liu, et al. RaptorX-Property: a web server for protein structure property prediction[J]. Nucleic Acids Research, 2016, Volume 44, Issue W1: W430-W435.

[24] Klausen MS, Jespersen MC, Nielsen H, et al. NetSurfP-2.0: Improved prediction of protein structural features by integrated deep learning[J]. Proteins, 2019, 87(6): 520-527.

[25]Madeira F, Park YM, Lee J, et al. The EMBL-EBI search and sequence analysis tools APIs in 2019[J]. Nucleic Acids Research, 2019 Jul, 47(W1): W636-W641

[26]Lu S, Wang J, Chitsaz F, et al. CDD/SPARCLE: the conserved domain database in 2020. Nucleic Acids Res. 2020, 48(D1): D265-D268.

[27] Tsirigos KD, Peters C, Shu N, et al. The TOPCONS web server for consensus prediction of membrane protein topology and signal peptides[J]. Nucleic Acids Res, 2015, 43(W1):W401-W407.

[28]Almagro Armenteros, J.J., Tsirigos, K.D., Sønderby, C.K. et al. SignalP 5.0 improves signal peptide predictions using deep neural networks[J]. Nat Biotechnol, 2019, 37(4): 420-423. 
bioRxiv preprint doi: https://doi org/10.1101/2020.02 21.951061; this version posted May 13,2020 . The copyright holder for this preprint (which was not certified by peer review) is the author/funder, who has granted bioRxiv a license to display the preprint in perpetuity. It is made available under aCC-BY 4.0 International license.

[29]Quintero FJ, Martinez-Atienza J, Villalta I, et al. Activation of the plasma membrane $\mathrm{Na}^{+} / \mathrm{H}^{+}$antiporter Salt-Overly-Sensitive 1 (SOS1) by phosphorylation of an auto-inhibitory C-terminal domain[J]. Proc Natl Acad Sci U S A, 2011, 108(6): 2611-2616.

[30] Källberg M, Wang H, Wang S, et al. Template-based protein structure modeling using the RaptorX web server[J]. Nat Protoc, 2012, 7(8): 1511-1522.

[31]Humphrey W, Dalke A, Schulten K. VMD: visual molecular dynamics[J]. J Mol Graph, 1996, 14(1): 33-28.

[32]Wass MN, Kelley LA, Sternberg MJ. 3DLigandSite: predicting ligand-binding sites using similar structures[J]. Nucleic Acids Res, 2010, 38(Web Server issue):W469-W473.

[33]Chenwei Wang, Haodong Xu, Shaofeng Lin, et al. GPS 5.0: An update on the prediction of kinase-specific phosphorylation sites in proteins. 2019, Submitted

[34]Blom N, sicheritz-ponten T, Gupta R, et al. Prediction of post-translational glycosylation and phosphorylation of proteins from the amino acid sequence[J]. Proteomics, 2004, 4 (6) : 1633-49.

[35]Wang D, Zeng S, Xu C, et al. MusiteDeep: a deep-learning framework for general and kinase-specific phosphorylation site prediction[J]. Bioinformatics, 2017, 33(24): 3909-3916.

[36] Wang D, Liang Y, Xu D. Capsule network for protein post-translational modification site prediction[J]. Bioinformatics, 2019, 35(14): 2386-2394.

[37]Szklarczyk D, Gable AL, Lyon D, et al. STRING v11: protein-protein association networks with increased coverage, supporting functional discovery in genome-wide experimental datasets[J]. Nucleic Acids Res, 2019, 47: D607-613.

[38]Eiru Kim, Sohyun Hwang, Insuk lee. SoyNet: a database of co-functional networks for deli-ine Max [J]. Nucleic Acids Research, 2017, Volume 45, Issue D1: D1082 -- D1089

[39]Shannon P, Markiel A, Ozier O, et al. Cytoscape: A software environment for integrated models of biomolecular interaction networks[J]. Genome Research, 2003, 13(11): 2498-504

[40]Goodstein DM, Shu S, Howson R, et al. Phytozome: a comparative platform for green plant genomics[J]. Nucleic Acids Res, 2012, 40 (Database issue) : D1178 - D1186.

[41] Barrett T, Wilhite SE, Ledoux P, et al. NCBI GEO: archive for functional genomics data sets--update[J]. Nucleic Acids Res, 2013, 41(Database issue): D991-5.

[42] Chow CN, Lee TY, Hung YC, et al. PlantPAN3.0: a new and updated resource for reconstructing transcriptional regulatory networks from ChIP-seq experiments in plants[J]. Nucleic Acids Res, 2019, 47(D1): D1155-D1 163.

[43] Chengjie, Chen Junting Feng, Bo Liu, et al. SRNAanno - a database repository of uniformly - annotated small RNAs in the plants [OL]. BioRxiv 771121. Doi: https://doi.org/10.1101/77112

[44]BLAST Scoring Parameters, e. Michael Gertz, 16 March 2005.

[45]S. Kumar, G. Stecher, K. TamuraMEGA7: Molecular Evolutionary Genetics Analysis Version 7.0 for Bigger Datasets [J]. Mol Biol Evol, 2016, 33: 1870-1874

[46]Bailey TL, Elkan C. Fitting a mixture model by expectation maximization to discover motifs in biopolymers[J]. Proc Int Conf Intell Syst Mol Biol, 1994, 2: 28-36.

[47]Laurie S, Feeney KA, Maathuis FJ, Heard PJ, et al. A role for HKT1 in sodium uptake by wheat roots[J]. Plant J, 2002, 32(2): 139-149.

[48]Zhu JK. Plant salt tolerance. TRENDS in Plant Science[J]. 2001, 6(2): 66-71. 
bioRxiv preprint doi: https://doi.org/10.1101/2020.0221.951061; this version posted May 13,2020 . The copyright holder for this preprint (which was not certified by peer review) is the author/funder, who has granted bioRxiv a license to display the preprint in perpetuity. It is made available under aCC-BY 4.0 International license.

[49]Batistic O, Kudla J. Plant calcineurin B-like proteins and their interacting protein kinases[J]. Biochim Biophys Acta, 2009, 1793(6): 985-992.

[50]Qiu QS, Guo Y, Dietrich MA, et al. Regulation of SOS1, a plasma membrane $\mathrm{Na}^{+} / \mathrm{H}^{+}$exchanger in Arabidopsis thaliana, by SOS2 and SOS3[J]. Proc Natl Acad Sci U S A, 2002,99(12): 8436-8441.

[51] Cheng NH, Pittman JK, Zhu JK, et al. The protein kinase SOS2 activates the Arabidopsis $\mathrm{H}(+) / \mathrm{Ca}(2+)$ antiporter CAX1 to integrate calcium transport and salt tolerance[J]. J Biol Chem, 2004, 279(4): 2922-2926.

[52] Belles - Boix E, Babiychuk E, Van Montagu M, et al. CEO1, a new protein from Arabidopsis thaliana, protects yeast against oxidative damage [J]. J FEBS Lett., 2000, 482:19-24.

[53] Katiyar - Agarwal S, Zhu J, Kim K, et al. The plasma be $\mathrm{Na}^{+} / \mathrm{H}^{+}$antiporter SOS1 interacts with RCD1 and functions provides in oxidative stress how in Arabidopsis [J]. Proc by Natl Acad Sci U S A, 2006,103 (49) : 18816-18821.

[54]Yu Y, Wang N, Hu R, et al. Genome-wide identification of soybean WRKY transcription factors in response to salt stress[J]. Springerplus, 2016, 5(1): 920. 